\title{
Exploring the influence of the North Pacific Rossby wave sources on the variability of summer atmospheric circulation and precipitation over the Northern Hemisphere
}

\author{
Ramón Fuentes-Franco $^{1,2}$ (D) $\cdot$ Torben Koenigk $^{1,2} \cdot$ David Docquier $^{3} \cdot$ Federico Graef $^{4} \cdot$ Klaus Wyser $^{1,2}$
}

Received: 19 January 2021 / Accepted: 3 February 2022 / Published online: 21 February 2022

(c) The Author(s) 2022

\begin{abstract}
The influence of Rossby waves emitted in the northeastern Pacific Ocean on the Northern Hemisphere's atmosphere during summer is analysed using ERA5 reanalysis and a new large ensemble performed with the EC-Earth3 model. The Rossby Wave Sources (RWS) trigger wave-like patterns arising from the upper troposphere of the north-eastern Pacific region, causing a response around the Northern Hemisphere with alternating regions of positive and negative correlation values between RWS and geopotential height at $500 \mathrm{hPa}$. Increased RWS intensity during summer is related to negative temperature anomalies over western North America, and positive temperature anomalies over eastern North America, concurrently with increased precipitation over the western subtropical Atlantic and Northern Europe during summer. Colder than normal conditions on the North Pacific Ocean intensify the RWS and its impact on the global atmospheric circulation. Different warm or cold states in the Pacific and Atlantic Oceans modify the atmospheric response to RWS, showing a change in the middle troposphere $(500 \mathrm{hPa})$ towards a more-wavy structure with cold Pacific conditions, and towards a less-wavy structure with a warm Pacific Ocean. Furthermore, the North Atlantic plays a very important role in hindering (in the case of warm water) or permitting (cold water) that Rossby waves generated in the Pacific modulate the atmospheric conditions over Europe.
\end{abstract}

\section{Introduction}

Circumglobal atmospheric Rossby waves influence strongly the meandering of the jet stream in the mid-latitudes around the globe, and therefore they have been associated with strong variability of precipitation during summer (Kornhuber et al. 2019) and winter seasons (Scaife et al. 2017; Dunstone et al. 2018; Li et al. 2020a, b). Rossby waves appear in the atmosphere as a result of vertical motion and uppertropospheric divergence causing, in turn, anomalous upperlevel vorticity. Since this upper-level vorticity induces the formation of Rossby wave trains, Sardeshmukh and Hoskins (1988) called them Rossby wave sources (RWS). RWS are

Ramón Fuentes-Franco

ramon.fuentesfranco@smhi.se

Rossby Centre, SMHI, Norrköping, Sweden

2 Bolin Centre for Climate Research, Stockholm University, Stockholm, Sweden

3 Royal Meteorological Institute of Belgium, Brussels, Belgium

4 CICESE, Ensenada, Mexico one of the mechanisms responsible for teleconnections (Qin and Robinson 1993).

Due to the strong impact of Rossby waves on extratropical weather and climate, it is relevant to study their source location. In this context, Nie et al. (2019) analysed the observed average spatial location of the RWS during winter and summer, finding that during winter, the main RWS in the Northern Hemisphere are located in East Asia, subtropical central and eastern Pacific, North America, subtropical North Atlantic, Mediterranean, and Arabian regions; while during summer over the Mediterranean, Arabian, and the Eastern Pacific close to North America. Nie et al. (2019) also assessed how some CMIP5 models simulate the intensity and location of RWS in the historical period, finding that CMIP5 models can capture the basic geographical distribution of RWS, but most models overestimate the RWS intensity in the subtropics and underestimate the RWS in the midlatitudes.

Rossby waves cause concurrent periods of above-normal temperatures around the globe, causing heat waves in North America, Western Europe and the Caspian Sea region (Kornhuber et al. 2019). Petoukhov et al (2013) and Kornhuber et al. $(2017,2020)$ showed that certain recurrent 
atmospheric circulation patterns are dominated by wavenumber 5-7 with a specific phase. According to Kornhuber et al. (2017), this preferred position and phase of the waves can be explained by the shape of the continents and oceans and the geographical location of prominent orographic features (like the Rocky Mountains and the Ural Mountains in the Northern Hemisphere), which cause surface temperature differences. For example, when there are high-temperature anomalies over land in the vicinity of the coastline, a northto-south component of the wind is set, due to thermal wind relation. The interaction of the jet stream with cyclonic and anticyclonic systems causes co-variability of weather in faraway regions (Branstator 2002; Kornhuber et al. 2020), like in the summers of 2006 and 2018 with dry conditions over western Central North America, Western Europe and Western Asia, or in 2012 with dry conditions over Central North America and Eastern Europe. These concurrent extreme dry (or wet) periods over different parts of the world caused by stalled Rossby waves have become more frequent in the last twenty years, though their significance is unclear. In their analysis made for the period 1979-2015, Kornhuber et al. (2017) found only three extreme events caused by Rossby waves before the year 2000, while six cases were found after the year 2000 .

One of the main teleconnection patterns having a strong impact on Northern Europe is the North Atlantic Oscillation (NAO). According to Feldstein (2003), the NAO variability can be triggered by Rossby waves propagating from the Tropics. Scaife et al. (2017b) showed that tropical rainfall explained $40 \%$ of the variance in the seasonal forecast of the NAO through Rossby waves. Further evidence for wave-like patterns associated with seasonal precipitation and the possible origins for these waves have been found to give a better process-based understanding of the interannual European climate variability. For example, Knight et al. (2017) suggested that the mechanism responsible for very wet winters in Northwestern Europe was the occurrence of Rossby waves generated over the Amazon region and the Tropical North Atlantic Ocean.

Li et al. (2020a, b) identified as potential Rossby wave source regions the Tropical Atlantic, the subtropical eastern Atlantic and, to a smaller degree, the subtropical eastern Pacific, especially over the Gulf of California. These Rossby wave sources caused by reduced precipitation in the Tropical Atlantic, and increased precipitation in the tropical eastern Pacific, cause Rossby waves into the North Atlantic that modulate the precipitation over Europe, finding that during some years even up to $60 \%$ of the precipitation anomalies in northern Europe can be explained by tropical precipitation anomalies.

Some of the teleconnections modulating the climate variability over Eurasia can be caused by tropical forcing, which causes an atmospheric response that propagates polewards (e.g., Hoskins and Ambrizzi 1993; Van Oldenborgh et al. 2000; Ding et al. 2011, Gastineau and Frankignoul 2015, Wulff et al. 2017, O'Reilly et al. 2018, Neddermann et al. 2019), for example, the circumglobal teleconnection pattern (CGT, Barnstator et al. 2002). Particularly for Europe, Wulff et al (2017) showed some evidence that the summer east Atlantic mode, which modulates the precipitation over the North Atlantic west of the British Isles, is forced by diabatic heating anomalies of opposing signs in the tropical Pacific and Caribbean. An important source of predictability for northern European climate from the Pacific has also been found by Fuentes-Franco and Koenigk (2020). They showed evidence of a large-scale link between the atmospheric variability over the central tropical Pacific during spring and the atmospheric circulation over the western Arctic and the North Atlantic-European sector during summer, which ultimately impacts the precipitation, especially over Northern Europe. This teleconnection mechanism, which in early spring has a similar spatial structure to the Pacific North American pattern, shows an atmospheric expansion in middle levels of the troposphere $(500 \mathrm{hPa})$ in the central subtropical Pacific, west of Hawaii, and is followed by cooler and wetter than normal summers over Northern Europe. Fuentes-Franco and Koenigk (2020) showed that this seasonally-lagged teleconnection shows systematic global changes, such as a strong anticyclonic flow and a decrease of sea ice concentration over the western Arctic, as well as higher atmospheric pressure and drier conditions over the European coasts of the eastern Mediterranean.

Previous studies have found that Rossby waves generated by sea surface temperature (SST) anomalies over the Gulf of Mexico and the Pacific impact the atmospheric circulation of the North Atlantic and European sectors (Saeed et al. 2014; Wulff et al. 2017; Neddermann et al. 2019). In turn, Luo and Lau (2020) have found that associated atmospheric changes over the North Pacific, linked to El Niño Southern Oscillation (ENSO) events, feature a CGT pattern over the mid-latitudes. Particularly they showed that in summers of transition to La Niña, this CGT pattern exhibits enhanced geopotential height and anomalous anticyclones over North Pacific, North America, Eastern Europe-Central Asia and northeastern Asia, and the jet stream generally shifts northward.

Although previous studies presented above show evidence of a link between Rossby waves generated in the northeastern Pacific and the Northern Hemisphere climate during summer, the possible mechanisms that generate these teleconnections and modulate them need further research. In this paper we investigate the role of RWS over the Pacific on the global atmospheric circulation, focusing in particular on their impact on the variability of precipitation during summer, which has received little attention so far. Using a large ensemble of model simulations, we also assess the robustness of the global atmospheric response caused by the 
RWS over the Pacific, and how different North Pacific and North Atlantic Ocean conditions impact such response. In Sect. 2, we describe the applied methodology and data used. The results and discussion are presented in Sect. 3 and summarized in the conclusions in Sect. 4.

\section{Methods and data used in this study}

\subsection{Rossby wave sources (RWS)}

Similarly to Scaife et al. (2017) and Nie et al. (2019), the RWS were derived from the barotropic vorticity equation in pressure coordinates as in Sardeshmukh and Hoskins (1988), James (1994), Trenberth et al (1998) and Holton and Hakim (2004). When expressing the horizontal winds in terms of their divergent $\left(v_{x}\right)$ and rotational components, the Rossby wave activity can be calculated as follows:

$R W S=-\nabla \cdot\left(v_{x} \zeta\right)=-\left(\zeta \nabla \cdot v_{x}+v_{x} \cdot \nabla \zeta\right)$

with $\zeta$ being the absolute vorticity. Therefore the RWS account for the rate of change of vorticity due to vortex stretching (first term) and to the vorticity advection by the divergent part of the wind (second term). According to Scaife et al. (2017), when analysing seasonal scales of RWS calculated at $200 \mathrm{hPa}$, using monthly wind data show very similar results to using daily data. Following Scaife et al. (2017), we calculated the RWS from monthly horizontal wind at $200 \mathrm{hPa}$. That level of the atmosphere shows the RWS intensity peak with strong convective outflow, divergent horizontal flow, a strong vorticity gradient, and maximum strength of the jet streams.

\subsection{Data}

To calculate RWS we used the monthly wind data at $200 \mathrm{hPa}$, and to analyse the impact of RWS on the atmosphere we used geopotential height at $500 \mathrm{hPa}(\mathrm{Z} 500)$, precipitation and air surface temperature from the European Centre for Medium-range Weather Forecasts (ECMWF) ERA5 reanalysis (Hersbach et al. 2020) [Copernicus Climate Change Service (C3S), 2017] at monthly scale during summer (June-August). This reanalysis has a horizontal resolution of approximately $31 \mathrm{~km}$. We used 40 years from 1979 to 2018. We also used sea ice concentration from the Version 2 of the EUMETSAT OSI SAF satellite observations (Lavergne et al. 2019).

A single simulation from models or a reanalysis is not enough to provide evidence of a global response to a particular forcing. Large ensembles, with multiple realizations, having each of them with a different development in the internal climate variability, are a valuable tool to separate a model's forced response from internal variability. In mid-and high latitudes, the internal variability of the atmosphere is high and this increases the uncertainty on how the atmosphere responds to a particular forcing. Therefore, in order to analyse the robustness of the atmospheric response to RWS in the Pacific, we used the Swedish Meteorological and Hydrological Institute Large Ensemble (SMHI-LENS, Wyser et al. 2021), which is a 50-member set of simulations performed with the EC-Earth3 model (Döscher et al. 2021) version 3.3.1. This model version comprises IFS cy36r4 for the atmospheric component at $80 \mathrm{~km}$ (N128) and NEMO3.6 including the sea ice model LIM3 for the ocean component using an ORCA1 grid with a 1-degree resolution over large parts of the globe and a mesh refinement at the equator. In the vertical, there are 91 levels in the atmosphere with the top-level at $1 \mathrm{~Pa}$, and 75 layers in the ocean. The period used for the SMHI-LENS is 1970-2014. The greenhouse gases, aerosol, land-use, stratospheric ozone and volcano forcings used for SMHI-LENS is the one provided for the historical experiment for CMIP6.

The use of a large number of ensemble members allows us to statistically distinguish the modulation caused by RWS maxima on precipitation and atmospheric circulation regardless of the high internal variability that exists during summer in the Northern Hemisphere (Deser et al. 2012, Horton et al. 2015).

\subsection{Relationship between RWS and other global variables during summer}

We first identified the region with the RWS maximum over the North Pacific. Then, we calculated the Pearson correlation coefficient between Z500 at every grid point and the spatially-averaged RWS (average over the region of maximum RWS over the North Pacific) across the whole time series at monthly scale. We considered only the summer months (June to August) in the ERA5 reanalysis for the period 1979-2018, since it is during summer when the largest RWS impacts have been identified (Sect. 1). Hence, we have a total of 120 months in the 40 years period. Before computing the correlation coefficients, the monthly climatologies and trends were removed. Regarding the significance of the correlation patterns, we used the Benjamini-Hochberg (1995) False Discovery Rate (FDR) test to exclude the expected proportion of false discoveries among all p-values. Following Wilks et al. (2016) we used an FDR significance level $\alpha_{\mathrm{FDR}}=0.10$.

Following the same methodology, we calculated correlation coefficients between precipitation, air surface temperature and sea ice concentration on the one hand, and RWS over the Pacific on the other hand. In the case of sea ice concentration, we used the OSI SAF satellite observations over the period 1993-2015. The same procedure was carried 
out on the SMHI-LENS for all variables for the 6750 summer months.

To disentangle the influence of the Pacific and Atlantic SST on the atmospheric response caused by the RWS emitted in the Pacific, we performed the same correlation calculation explained above for cold and warm ocean conditions in the two ocean basins. We considered cold (warm) conditions in the summer months with SST below (above, respectively) the summer climatological value for both ocean basins separately.

\section{Results and discussion}

\subsection{Impact of Pacific RWS on the Northern Hemisphere summer climate in ERA5}

The spatial distribution of the climatology of RWS over the Northern Hemisphere calculated from the ERA5 reanalysis shows that the summer RWS maxima in the Northern Hemisphere are located over the Eastern Pacific extending from the central Pacific to the North American coasts (Pac$\mathrm{Cal}$ ), the subtropical North Atlantic (TNA), the Mediterranean area (Medit), Middle East (MidEast) (Fig. 1); while the minima of the regions with negative RWS (also called Rossby wave sinks) are located over East Asia, and expand eastward towards the central North Pacific.

The correlation between PacCal RWS and Z500 shows a wave-like pattern with a series of alternated regions with significant positive and negative correlation values around the globe (Fig. 2a), starting from the northeastern Pacific

ERA5 RWS JJA

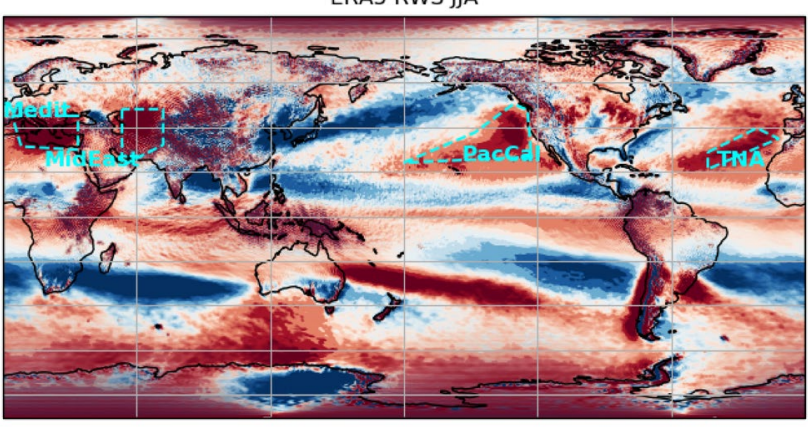

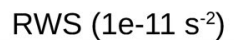

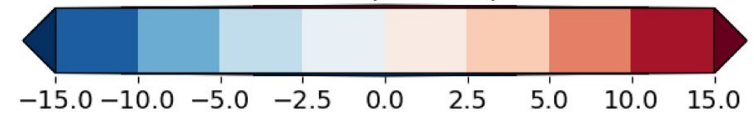

Fig. 1 RWS climatology during the JJA season for ERA5. Main RWS regions are enclosed in cyan. RWS maxima in the Northern Hemisphere are enclosed over the Eastern Pacific extending from the central Pacific to the North American coasts (PacCal), the subtropical North Atlantic (TNA), the Mediterranean area (Medit) and over the Middle East (MidEast)
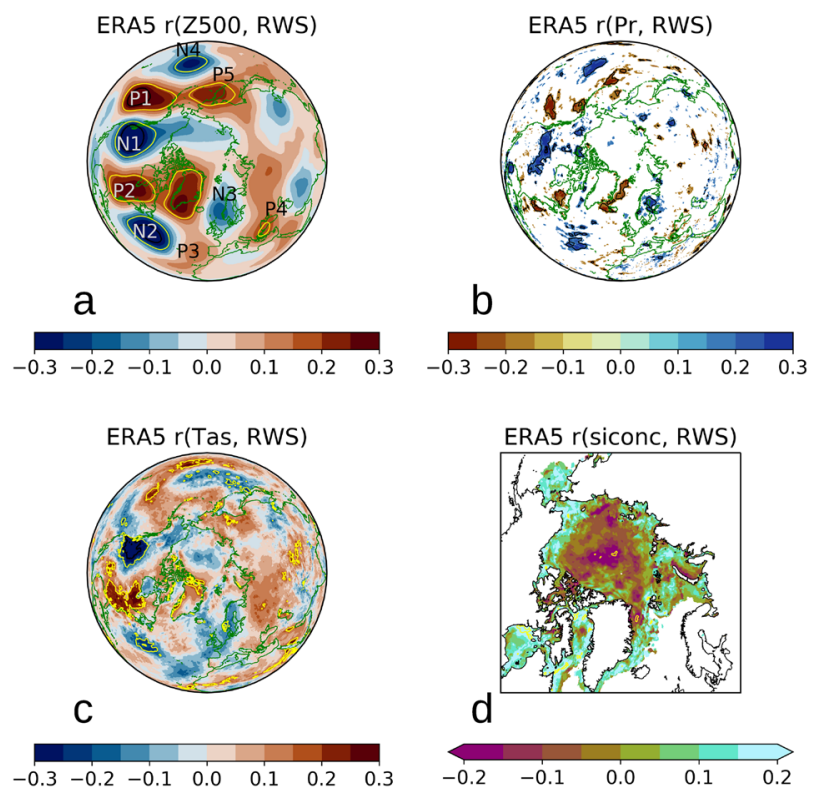

Fig. 2 Pearson correlation between monthly PacCal RWS and a geopotential height at $500 \mathrm{hPa}$ (Z500) for the summer months June to August. b As a but for precipitation. c As a but for surface temperature. d As a but for sea ice concentration. PacCal RWS, Z500, precipitation and surface temperature come from ERA5 for the period 1979-2018, while sea ice concentration comes from OSI SAF in the 1993-2015 period. Yellow (a-d) and magenta (b) contours show the regions that show significant correlation values at $\mathrm{p}<0.05$. Black contours show grid points that passed the Benjamin/Hochberg false discovery rate test with $\alpha=0.1$. Regions highlighted in a show centers of significant positive (P1-5) and negative (N1-4) correlation values, further described in Sect. 3.1. Only grid points with significant correlation $(\mathrm{p}<0.1)$ are shown for precipitation

(positive, P1 in Fig. 2a), followed eastwards by western North America (negative, N1), eastern North America that extends northwards over Greenland (positive, P2), the northwestern Atlantic ocean (negative, N2), a small region over the eastern North Atlantic close to the Iberian peninsula (positive, P3), the Norwegian Sea (negative, N3), southeastern Europe (positive, P4), a wide area of positive but not significant correlation values between areas $\mathrm{P} 4$ and P5, and eastern Siberia and the Sea of Okhotsk (positive, P5). Lastly, the western North Pacific (negative, N4) closes the loop and lies between and south of P1 and P5. We considered the eastward direction since the synoptic Rossby waves interact with the background flow, which is eastward on average, although the Rossby waves would in principle travel westward, however with a weaker phase speed than the eastward background flow. Only regions P1, P2, N1 and N2 passed the FDR test but this might be due to the small sample (120 data points per grid point).

The spatial correlation patterns show similarities with the CGT (Saeed et al. 2014), since the regions of correlation P2, N2, P3, N3 and P4 of Fig. 2a are spatially coincident with 
the regions of high weights of the CGT pattern, that is the leading first.

EOF mode of $200 \mathrm{hPa}$ meridional wind during summer for the region constrained by longitudes $100 \mathrm{~W}-100 \mathrm{E}$ and latitudes $20 \mathrm{~N}-80 \mathrm{~N}$. The CGT shows a constrained signal only to the eastern US, the North Atlantic and Eurasia, with no signal over the Pacific nor western North America. The differences in the spatial patterns of regions with high and low pressures are that the CGT correlated negatively with the PacCal RWS, the centers of high and low pressures associated with the CGT are coincident to the areas of significant PacCal RWS-Z500 correlation, except over the eastern North Atlantic, where the CGT shows a center of low pressure in the positive phase, west of the British isles.

Despite the much noisier spatial pattern, regions with positive significant correlation values between PacCal RWS and precipitation are found over geographical areas coincident with a negative correlation between PacCal RWS and Z500 (N1-N4) and vice-versa (Fig. 2b). The correlation patterns obtained when using observational data from the Global Precipitation Climatology Project version 2.3 are very similar to those obtained using ERA5 (not shown). For temperature, the regions of positive correlation with PacCal RWS, are coincident in sign and location with those of Z500 (Fig. 2c). Hence, although the relationship is not linear, interpreting the correlations found means that an increased RWS intensity in the PacCal region perturbs the atmosphere in such a way that areas P1-P5 tend to show expanded atmosphere together with dry and warm anomalies, and the contrary for areas N1-N4. Small regions within the significant correlation areas passed the FDR test for temperature and precipitation.

Previously, Kornhuber et al. (2020) have also mentioned that Rossby waves with wavenumbers 5 and 7 have a preferred phase position and constitute recurrent atmospheric circulation patterns in summer. The wave-like pattern shows similarities to the wavenumber 5 pattern shown by Kornhuber et al. (2020), who reported that with wavenumber 5, co-occurring heatwaves can be present over Central North America, Eastern Europe and East Asia. However, the spatial patterns that Kornhuber et al. (2020) show are displaced towards the west compared to the patterns emerging in this study from PacCal RWS.

The negative correlation between PacCal RWS and sea ice concentration (Fig. 2d) is in agreement with previous results from Screen and Francis (2016), who found that significant anomalous temperatures over the Pacific ocean, similar to a negative phase of PDO, are related to a decrease in sea ice concentration in the Arctic. In the context of an increased RWS over the PacCal region, anomalous southerly winds are occurring over the central North Pacific associated with the west part of anticyclonic circulation (high Z500 values from Fig. 2a), which advect warm air into the western
Arctic. Screen and Francis (2016) argued that enhanced iceloss-driven Arctic warming during PDO- is partly due to the atmospheric circulation during PDO- being more effective than $\mathrm{PDO}+$ at transporting sea-ice-driven temperature anomalies from the peripheral Arctic seas into the central Arctic. Our results suggest that this happens due to a wavelike pattern produced by enhanced RWS. However, very few grid points in the central Arctic, Baffin Bay, Denmark strait and Davis strait show significant correlation $(p<0.05)$ and none of them passed the FDR test.

We have found that different regions around the Northern Hemisphere (P1-P5 and N1-N4) experience consistent significant impacts across different variables (Z500, precipitation and surface air temperature) modulated by the RWS PacCal, which shows that the upper atmospheric dynamics over the PacCal region plays an important role in triggering a global teleconnection. The relationship between RWS over $\mathrm{PacCal}$ and the different variables over regions with significant correlation (P1-P5 and N1-N4) is also found when composites of precipitation, Z500, surface temperature and sea ice concentration are calculated based on the summers with highest PacCal RWS and summers with lowest PacCal RWS values (not shown).

The pattern of correlation between PacCal RWS and geopotential height or precipitation (Fig. 2a, c), is similar to the cases analysed by Kornhuber et al (2017) who showed how the circulation patterns providing conditions for heatwaves around the globe can be caused by wave resonance between a stationary wave and a free wave with the same wave-length, in which case the wave amplitudes are summed up and therefore cause concurrent heat waves in regions like western Canada/United States, Europe and Japan.

\subsection{Impact of Pacific RWS on the Northern Hemisphere summer climate in the SMHI-LENS}

In this section, we analyse how the SMHI-LENS ensemble represents the global response of the RWS generated over the Pacific. To do this, we first calculated the RWS over the 50 SMHI-LENS ensemble members. The ensemble average of the summer RWS climatology (Fig. 3a) reproduces the geographical location of the four RWS in ERA5 (Fig. 1). When assessing the ensemble bias (Fig. 3b), we found that the PacCal and Medit RWS are slightly underestimated, and the MidEast RWS is overestimated in the SMHI-LENS. The TNA RWS is well represented, being the RWS that agrees best with ERA5.

To assess the impact of PacCal RWS in the global atmosphere, we repeated the correlation analysis performed with ERA5. In this case, we used the monthly values of each of the three months (June, July and August) from the 2250 simulated summers (45 simulated years [1970-2014] for each of the 50 ensemble members), providing a total of 

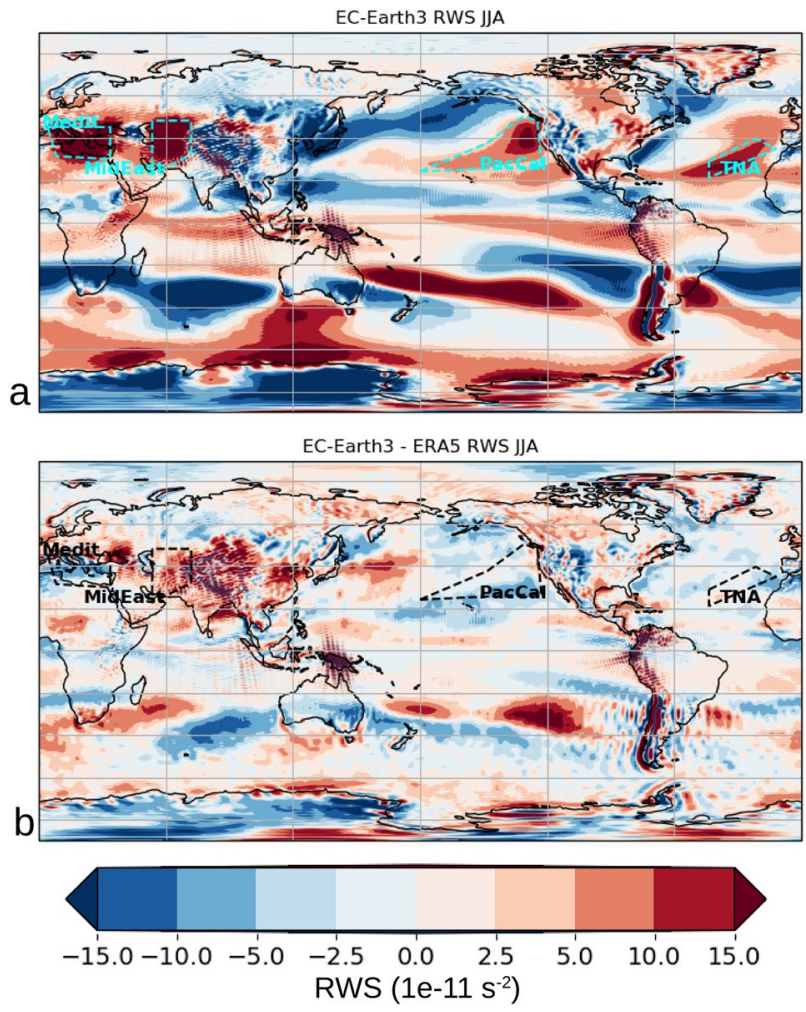

Fig. 3 Average of RWS climatology during JJA season across all SMHI-LENS ensemble members. b SMHI-LENS ensemble average minus ERA5 RWS climatology. As for Fig. 1, the main RWS regions are enclosed in cyan

6750 months. After removing the linear trend over time to all variables (RWS, Z500, precipitation, air surface temperature and sea ice concentration) in every ensemble member, the different simulations from the different ensemble members were concatenated to calculate correlations between PacCal RWS and Z500, precipitation, surface temperature and sea ice concentration over all ensemble members.

For the correlation between PacCal RWS and Z500 (Fig. 4a) in SMHI-LENS, we found that the spatial pattern shows the same number of significant regions as ERA5 (Fig. 2a), with P1-P5 and N1-N4, however with some differences in their extension and with larger areas of significance compared to ERA5. Note also the smoother signal in SMHI-LENS compared to ERA5 due to the much larger number of months considered in the computation (6750 vs. 120 months). The areas of significant correlation show differences over the North Atlantic Ocean, with P2 confined to continental North America, and not extending as far to the north to Greenland as in ERA5. The area P3 shows a larger area compared with ERA5, covering all the eastern subtropical North Atlantic and reaching Spain, the west coast of France and the British Isles. N3 in turn is located eastwards, compared to the position found in ERA5, extending northwards covering the Barents Sea.
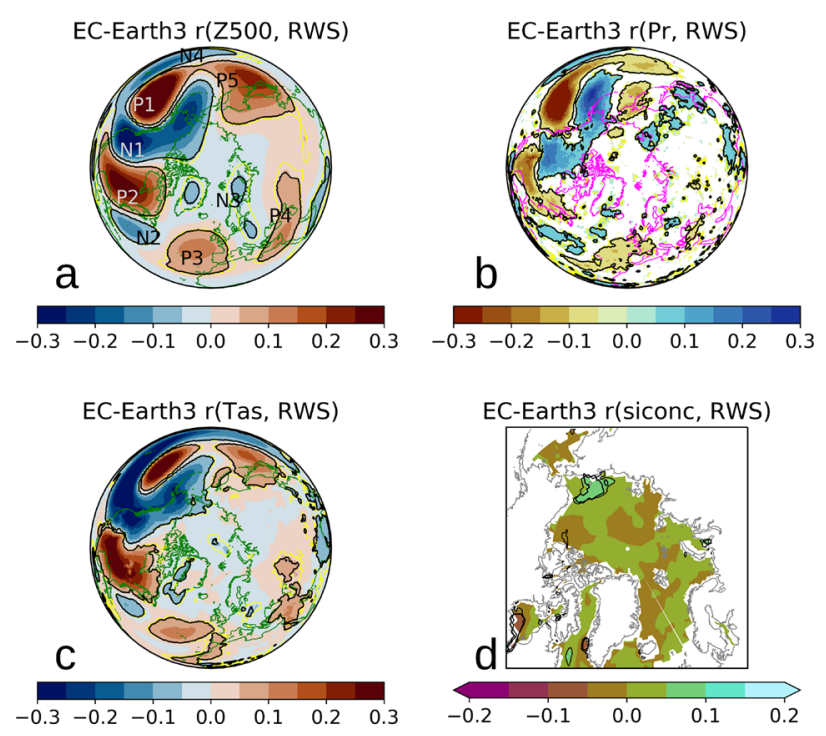

Fig. 4 Pearson correlation between monthly PacCal RWS and a geopotential height at $500 \mathrm{hPa}$ (Z500) for the summer months June to August. b As a but for precipitation. c As a but for surface temperature. d As a but for sea ice concentration. All data come from SMHI-LENS within the period 1970-2014. Yellow contours show the regions that show significant correlation values at $p<0.05$. Black contours show grid points that passed the Benjamin/Hochberg false discovery rate test with $\alpha=0.1$. Regions highlighted in a show centers of significant positive (P1-5) and negative (N1-4) correlation values, further described in Sect. 3.1. Only grid points with significant correlation $(\mathrm{p}<0.1)$ are shown for precipitation

Finally, in contrast to ERA5, in the SMHI-LENS a region of significant positive values connected the areas $\mathrm{P} 4$ and P5 along Eurasia. We assessed the areas where the SMHILENS and ERA5 match in the sign of the correlation, and we found that regions with higher similarity are the eastern north Pacific and North America with a match in $77 \%$ of the area, the western north Pacific and east Asia with 67\%, and Europe with $60 \%$ of the area (Figure S1a of the supplementary material), while the regions with lower match are the Arctic, Asia and the Atlantic ocean with 30\%, 49\% and 53\% match respectively. For geopotential height, there is a tendency to show less match on the correlation patterns, on grid points located farther away from the origin of the signal PacCal.

Although the results obtained with the global climate model might be subject to internal model biases regarding its atmospheric circulation, wave-like patterns arising from the upper troposphere northeastern Pacific region are a consistent feature across the ensemble members and in many cases consistent with ERA5 (Figure S2). Furthermore, the match on the correlation patterns between every ensemble member with ERA5 (Figure S2) and with the SMHI-LENS ensemble mean (Figure S3) show similar results, having great similarity in regions near the PacCal RWS, and decaying away from the PacCal RWS maxima. 
As for ERA5, positive significant correlation values between PacCal RWS and precipitation are found over geographical areas coincident with a negative correlation between PacCal RWS and Z500 (N1-N4) and vice-versa (Fig. 4b). For temperature, the regions of positive correlation with PacCal RWS are coincident in sign and location with those of Z500 (Fig. 4c). The main difference in correlation between PacCal RWS and precipitation is that the SMHILENS showed positive correlation values over Greenland, in contrast to the negative values found in ERA5. Furthermore, the positive correlation values over Europe are located over the Baltic countries while in ERA5 they are located in the Baltic Sea including Sweden, Finland and the Baltic countries. For the RWS and precipitation correlation, the ERA5 and SMHI-LENS show the highest match over North America, the northwest Pacific Ocean and Europe with 67\%, $57 \%$ and $54 \%$ match (Figure S1b).

No clear patterns are found in the correlation between PacCal RWS and sea ice concentration, except for a significant positive correlation on the East Siberian Sea (Fig. 4d). The ERA5 and SMHI-LENS show a low match with only $44 \%$ of the grid points showing the same correlation sign (Figure S1d).

\subsection{Influence of North Pacific and North Atlantic SST on the RWS-induced atmospheric patterns}

Since the ocean and the atmosphere interact with each other, we assess how much the wave pattern that arises from correlating the PacCal RWS and Z500 is modified by different states in the North Pacific and North Atlantic Oceans.

Warm SST anomalies over the North Pacific Ocean reduce the intensity of the PacCal RWS (Fig. 5), and the SST over the Atlantic might play a role in the atmospheric response caused by the PacCal RWS.

Therefore to assess this, for both of these oceans, we performed the same correlation analysis as explained in

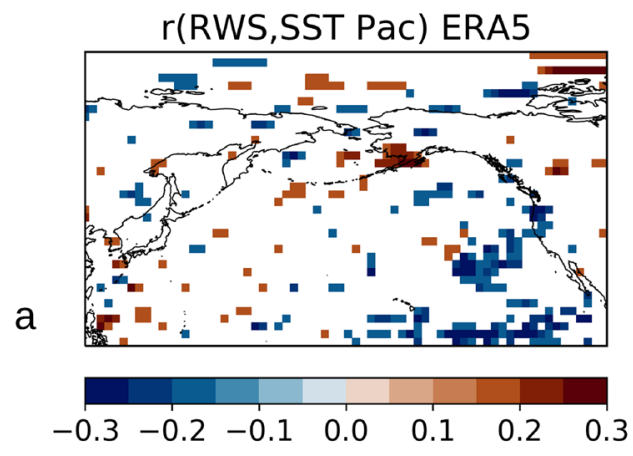

Fig. 5 Pearson correlation between monthly detrended SST conditions over the North Pacific and monthly detrended RWS for a ERA5 and $\mathbf{b}$ SMHI-LENS. The region where the SST were taken lies among the coordinates $155 \mathrm{~W} 57 \mathrm{~N}, 140 \mathrm{~W} 50.5 \mathrm{~N}, 130 \mathrm{~W} 30 \mathrm{~N}, 118 \mathrm{~W}$
Sect. 2.3 for cold and warm ocean conditions, considering cold (warm) conditions as the summer months with SST below (above, respectively) the summer climatological value.

We found that there is a clear influence of the North Atlantic Ocean on the shape of the PacCal RWS-Z500 correlation pattern, with the cold conditions showing an intensified positive correlation over the $\mathrm{P} 3$ area and an intensified significant negative correlation in the $\mathrm{N} 3$ area over North Europe (Fig. 6a, d) compared to the analysis including all months (Figs. 2a and 4a). The warm Atlantic case shows weaker correlations (in absolute values) and smaller N2 and $\mathrm{P} 3$ regions than in the cold case. Furthermore, the area N3 of significant negative correlation found in the cold case does not appear in the case of warm Atlantic (Fig. 6b, e). Both ERA5 and SMHI-LENS show consistent intensified correlations (in absolute value) in the N2, P3 and N3 areas when the difference between cold and warm Atlantic conditions is calculated (Fig. 6c, f), showing a tripole over the North Atlantic and Europe. Since the sample size for ERA, in this case (and following cases), is much smaller, none of the cases has passed the FDR test. In contrast, the SMHI-LENS passes the FDR, though over smaller areas that have passed the FDR compared to the significant value $\mathrm{p}<0.5$.

Consistently to the changes in circulation patterns observed in the cold and warm states in the North Atlantic (Fig. 6), under cold Atlantic conditions the correlation of PacCal RWS and precipitation (Fig. 7a, d) shows increased positive correlation over Northern Europe due to the intensified negative correlation in the $\mathrm{N} 2$ area compared to the all-months correlation (Figs. $2 b$ and $4 b$ ). ERA5 shows maximum correlation values in the Fennoscandian peninsula, while the SMHI-LENS showed maximum correlation values over regions in Norway and the Baltic countries (Fig. 7a, d). Wider areas of positive and negative RWS-precipitation correlation values are found on the areas $\mathrm{N} 2$ and $\mathrm{P} 3$, over the western and eastern North Atlantic respectively (Fig. 7a, d)

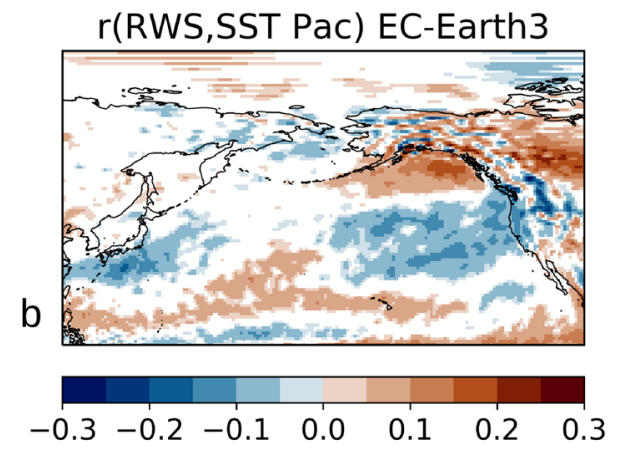

$33 \mathrm{~N}, 124.5 \mathrm{~W} 48.7 \mathrm{~N}, 138 \mathrm{~W} 59 \mathrm{~N}$. ERA data is for the 1979-2018 period. Data from SMHI-LENS is for the period 1970-2014. Only grid points with significant correlation $(\mathrm{p}<0.1)$ are shown 

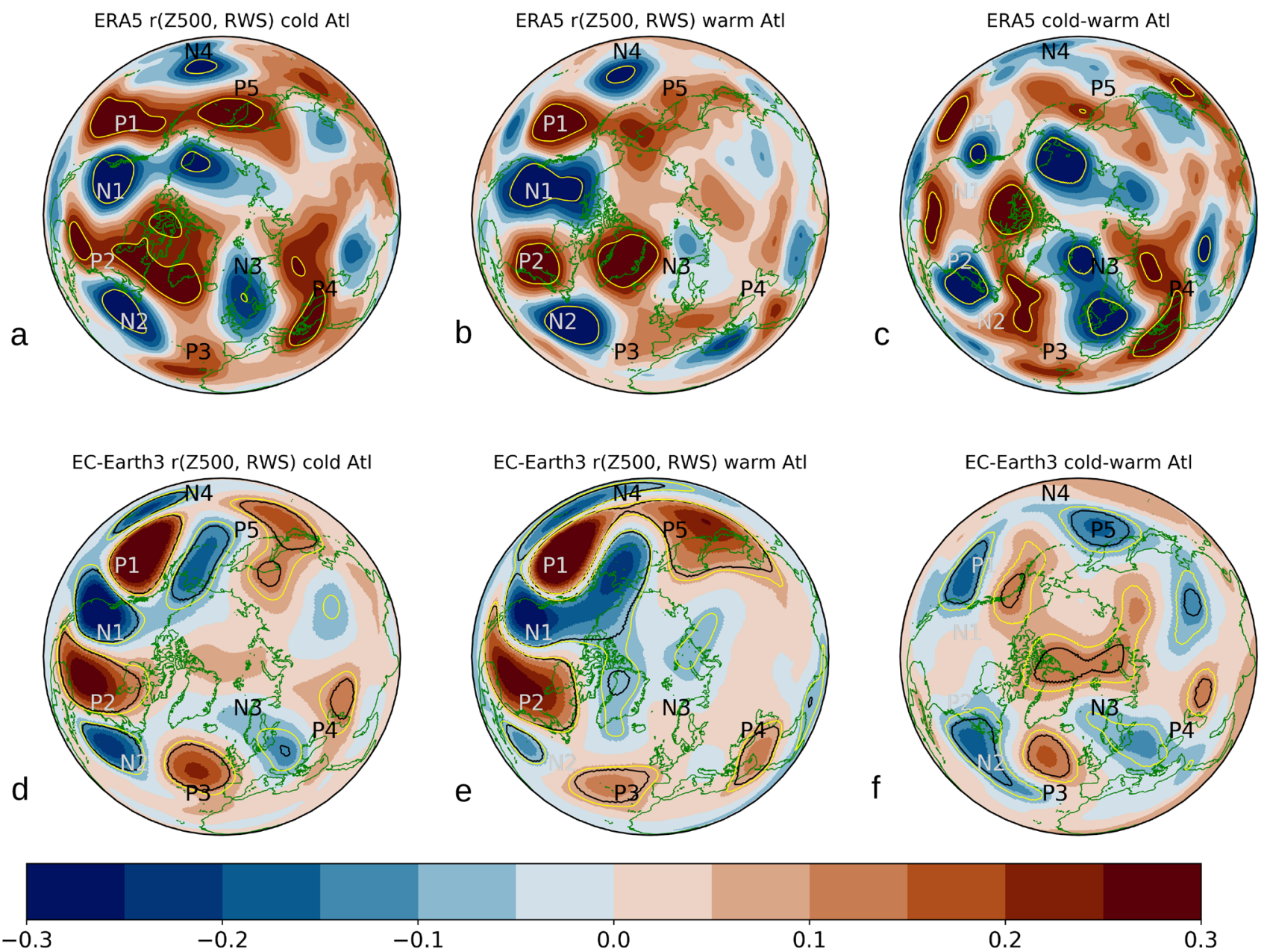

Fig. 6 Pearson correlation between monthly RWS and Z500 for the summer months (June to August) with a colder and b warmer than average North Atlantic SST for ERA5. $\mathbf{c}$ Difference between $\mathbf{a}$ and $\mathbf{b}$. d-f As a-c, respectively, but for SMHILENS. Yellow contours show the regions that show significant correlation values at $p<0.05$. Black contours show grid points that passed the Benjamin/Hochberg false discovery rate test with $\alpha=0.1$. The region taken as North Atlantic lies among the coordinates $57 \mathrm{~W} 60 \mathrm{~N}, 57 \mathrm{~W} 37 \mathrm{~N}, 18 \mathrm{~W} 40 \mathrm{~N}, 5 \mathrm{~W}$ $67 \mathrm{~N}$ and $30 \mathrm{~W} 67 \mathrm{~N}$. The periods used are 1979-2018 for ERA5 and 1970-2014 for SMHI-LENS. The data used to produced the figure was detrended and the monthly climatologies removed

the Arctic and the North Atlantic Ocean with 13\% and 41\% match respectively. The matches for precipitation also are slightly higher during the cold North Atlantic conditions than in warm North Atlantic, especially over Europe and Asia, but the difference is smaller than in Z500 (Figure S4c, d).

When considering the months of warm and cold Pacific, the PacCal RWS-Z500 correlation pattern also shows changes compared to the all-month correlation pattern, with the warm case showing stronger and larger areas of correlation over the Pacific, North America and East Asia (P1, N1, P2 and P5, Fig. 8b, e). For the SMHI-LENS particularly, this correlation shows a zonal structure, with positive correlation values dominating the subtropics and negative correlation values over the polar latitudes. The cold case shows weaker correlation patterns over the Pacific and a not significant 

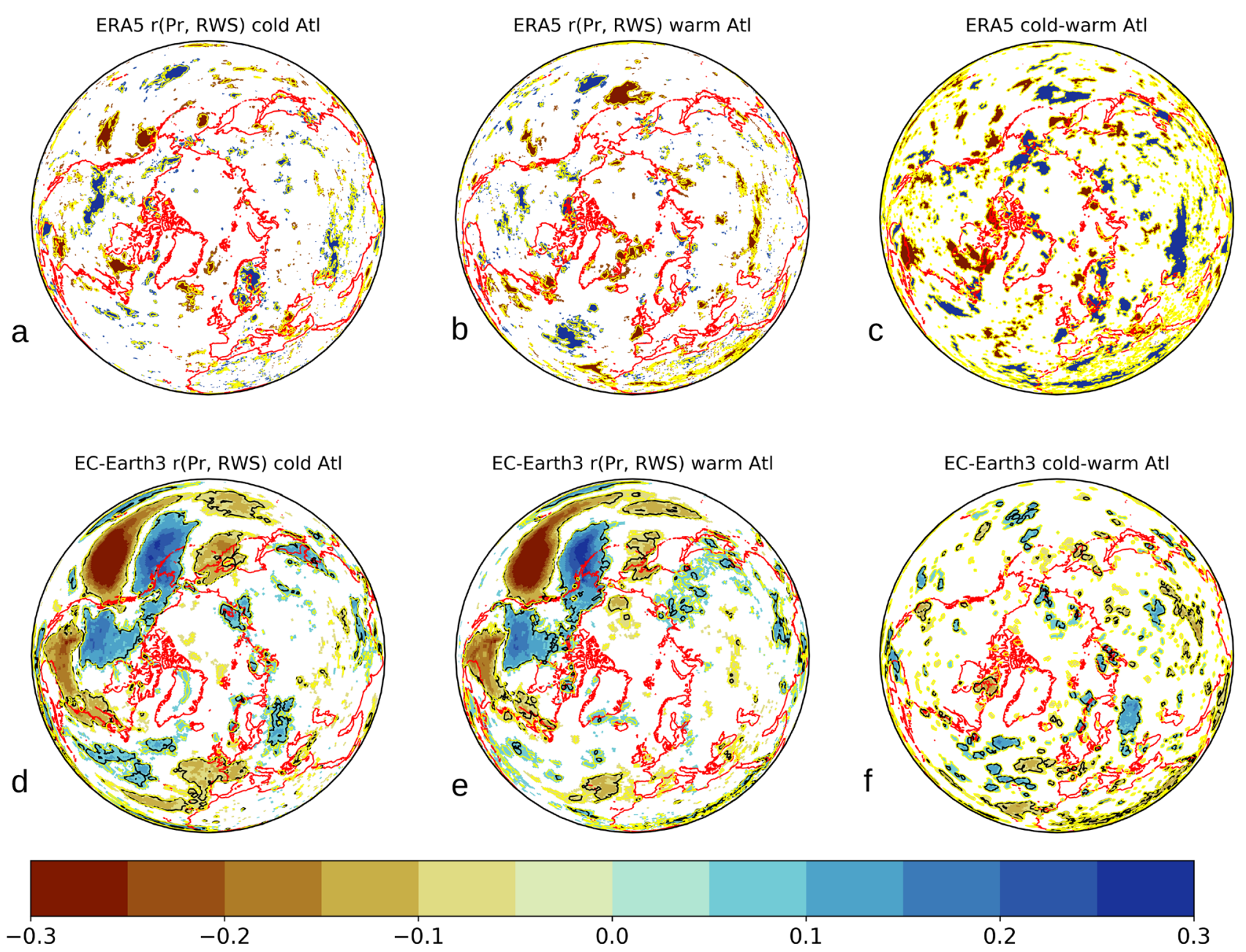

Fig. 7 As Fig. 6 but for precipitation. Only grid points with significant correlation $(\mathrm{p}<0.1)$ are shown

negative correlation over Northern Europe (N3) in ERA5 (Fig. 8a). In the SMHI-LENS, the N3 correlation appears with significant values located in Central Southern Europe (Fig. 8d). Both the ERA5 and SMHI-LENS shows consistent weakened correlations in the P5, P1 and N4 areas and intensified correlation in the P2, N2, P3, P4 and N3 (displaced towards Central-Southern Europe) areas when the difference between cold and warm northeastern Pacific conditions is calculated (Fig. 8c, f). North America, Europe and the North Atlantic Ocean show similar percentages of matching signs of the correlation for both cold and warm cases, with more than $75 \%, 65 \%$ and $54 \%$ of the grid points match, while Asia and the Arctic show $60 \%$ and $37 \%$ respectively for the cold Pacific case and $44 \%$ and $13 \%$ respectively for the warm Pacific case (Figure S5a, b).

For months with cold northeastern Pacific, the correlation of PacCal RWS and precipitation shows positive values over Northern Europe in ERA5 (Fig. 9a), while the areas of positive correlation extend from North to Central Europe in the SMHI-LENS (Fig. 9d) larger than the all-months pattern.
For the warm Pacific months, both ERA5 and SMHI show only significant areas over the Pacific (negative) and North America (positive) (Figs. 9b, e). Both ERA5 and the SMHILENS show the main difference between cold and warm Pacific months in negative correlation values over Greenland, northern Siberia and in the eastern subtropical Atlantic, and positive correlation values over western subtropical North Atlantic, Northern Europe, Southern Siberia and China (Fig. 9c, f). Compared to the warm Pacific case, the cold Pacific case shows a higher percentage of grid points with an ERA5-SMI-LENS matching on the PacCal RWSprecipitation correlation sign in all areas of the northern hemisphere (Figure S5c,d). This might be due to the fact that a cold northeastern Pacific would have more intense PacCal RWS than the warm case, and therefore there is a stronger atmospheric response is produced in ERA5 and reproduced in SMHI-LENS.

The significant areas of PacCal RWS-Z500 correlation considering the warm and cold SST conditions for both oceans, show differences with ERA, however, the structure 

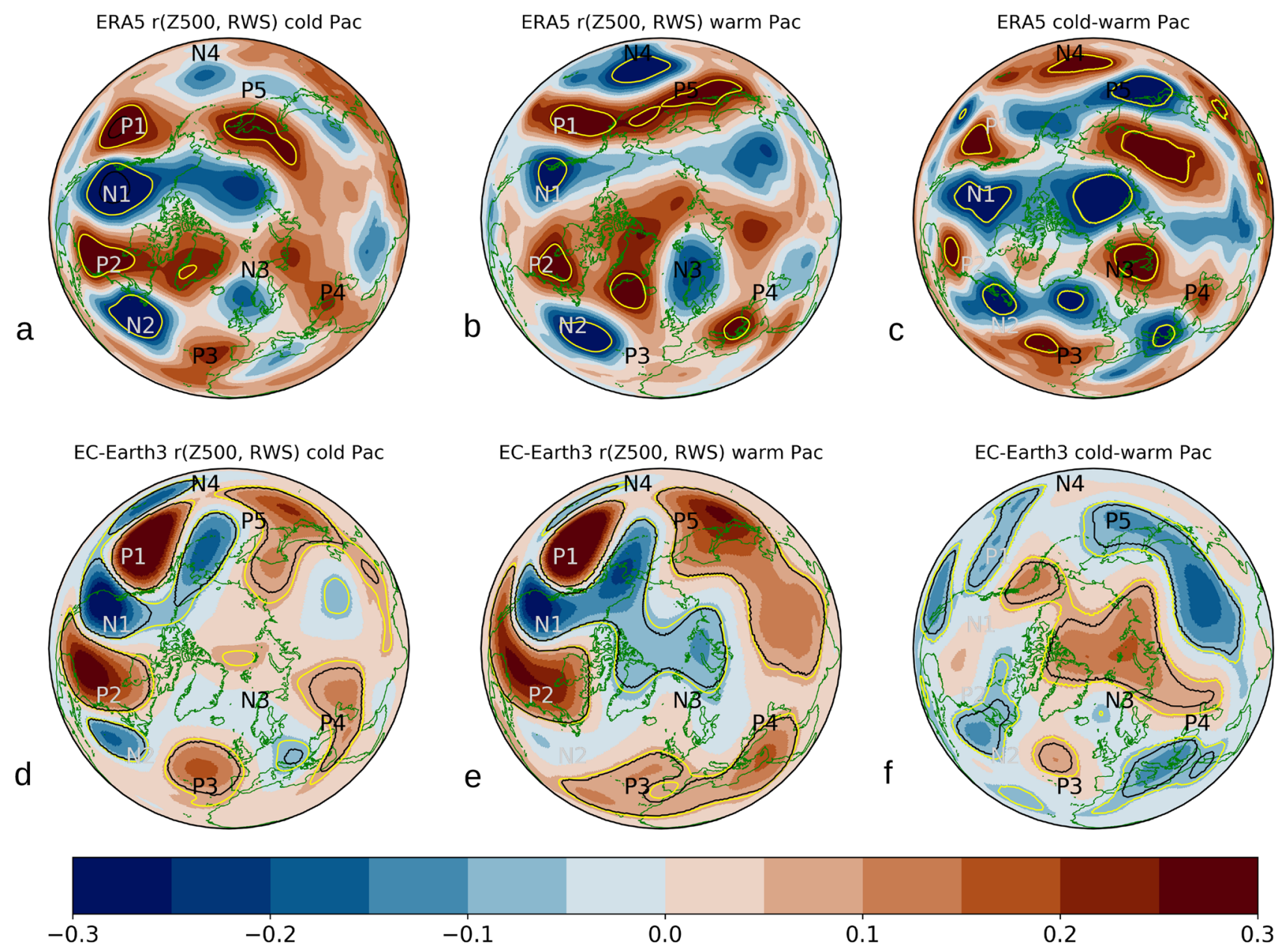

Fig. 8 Pearson correlation between monthly RWS and Z500 for the summer months (June to August) with colder than average Northeastern Pacific SST, for a ERA5. b Same as a for as summer months with warmer than average Northeastern Pacific SST. c Difference between a minus $\mathbf{b}$. $\mathbf{d}-\mathbf{f}$ as a-c respectively but for SMHI-LENS. The region taken as Northeastern Pacific lies among the coordinates 155 W $57 \mathrm{~N}, 140 \mathrm{~W} 50.5 \mathrm{~N}, 130 \mathrm{~W} 30 \mathrm{~N}, 118 \mathrm{~W} 33 \mathrm{~N}, 124.5 \mathrm{~W}$
$48.7 \mathrm{~N}, 138 \mathrm{~W} 59 \mathrm{~N}$. The periods used are 1979-2018 for ERA5 and 1970-2014 for SMHI-LENS. Yellow contours show the regions that show significant correlation values at $\mathrm{p}<0.05$. Black contours show grid points that passed the Benjamin/Hochberg false discovery rate test with $\alpha=0.1$. The data used to produced the figure was detrended and the monthly climatologies removed

simultaneous warm or cold states in the North Atlantic and northeastern Pacific (Figs. 10 and 11), and we identified specific features dominated by a specific state in every basin regardless of the state of the other. Noisier correlation patterns are found in ERA5, compared to SMHI-LENS, which is due to a smaller sample in ERA5 with approx. 40 months used to produce every combination of ocean states, while for the SMHI-LENS for every map more than 1600 summer months are used. The main features for every ocean and state were:

The warm Pacific and warm Atlantic cases show very little agreement between ERA5 and the SMHI-LENS for both PacCal RWS-Z500 (Fig. 10a, b) and PacCal RWS-precipitation (Fig. 11a, b) correlation patterns with the lowest number grid points matching in all the northern hemisphere 

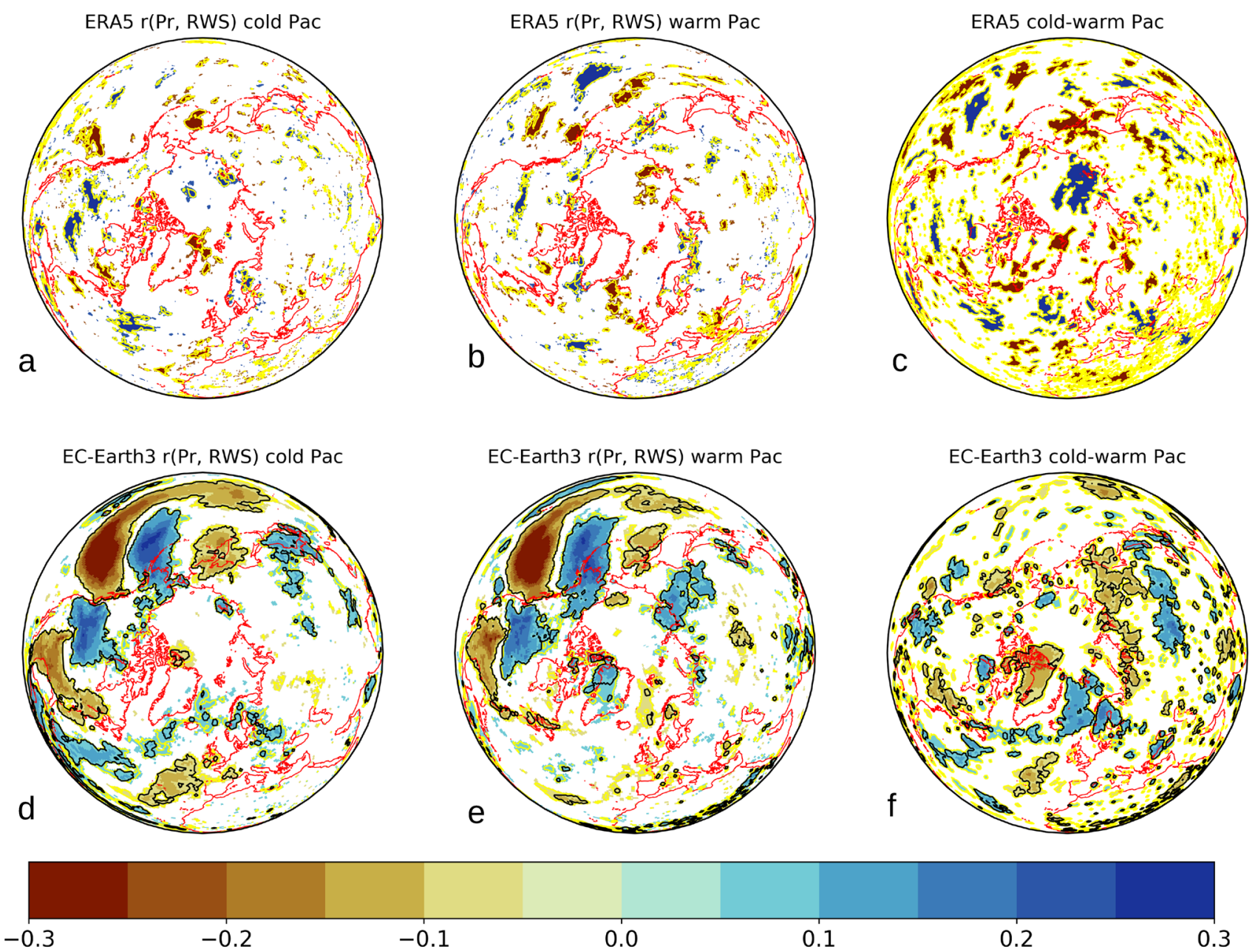

Fig. 9 As Fig. 8 but for precipitation. Only grid points with significant correlation $(\mathrm{p}<0.1)$ are shown

compared to the other cases (Figure S7d, S8d). Showing only similar correlation patterns only in areas close to the RWS, i.e. over North America, the Pacific Ocean and East Asia. The lack of agreement between ERA5 and SMHILENS might be due to the fact that during warm Pacific conditions, the PacCal RWS intensity is reduced, causing a weaker atmospheric response in the atmosphere.

The cold Pacific and warm Atlantic case shows the largest agreement between ERA5 and the SMHI-LENS over Asia and Europe for the PacCal RWS-Z500 correlation patterns (Fig. 10c, d, Figure S7b), with $61 \%$ and $73 \%$ of the grid points matching in the sign of the correlation, but these areas do not show significant patterns. Regions of significant negative correlation and match between ERA5 and SMHILENS are found over the eastern tropical Atlantic close to the southern European coast (Figs. 6b, 11c, d).

The cold Atlantic cases have a significant negative RWS-Z500 correlation over Northern Europe (N3) regardless of the Pacific state for both SMHI-LENS and ERA5 (Fig. 10e-h). Positive PacCal RWS-precipitation correlation is shown over northern Europe (Fig. 11e-h). For precipitation, the two cases with cold Atlantic conditions showed in all areas the largest number of grid points matching in the sign of correlation except over Asia.

For the European continent, the RWS emitted in the Pacific showed significant links during cold phases of the Atlantic (Figs. 8a, d, 9a, d), but this link is reinforced for precipitation when the Pacific is also in a cold phase (Fig. $11 \mathrm{~g}$, h).

Of particular relevance are the areas that show statistical significance in the PacCal RWS-precipitation correlation patterns and matching in the correlation sign between ERA and SMHI-LENS, especially those areas not near to the PacCal RWS. Examples of these areas are the subtropical Northwestern Atlantic and Northern Europe during cold Atlantic and cold Pacific (see Fig. 7a, d, Figure S4c, Fig. 9a, d, Figure S5c, Fig. 11g, h and Figure S8a) that show significant positive values or the eastern subtropical Atlantic near the Iberian Peninsula during cold Pacific with negative significant values (see Fig. 9a, d, Figure S5c, Fig. 11c, d, Figure S8b). 

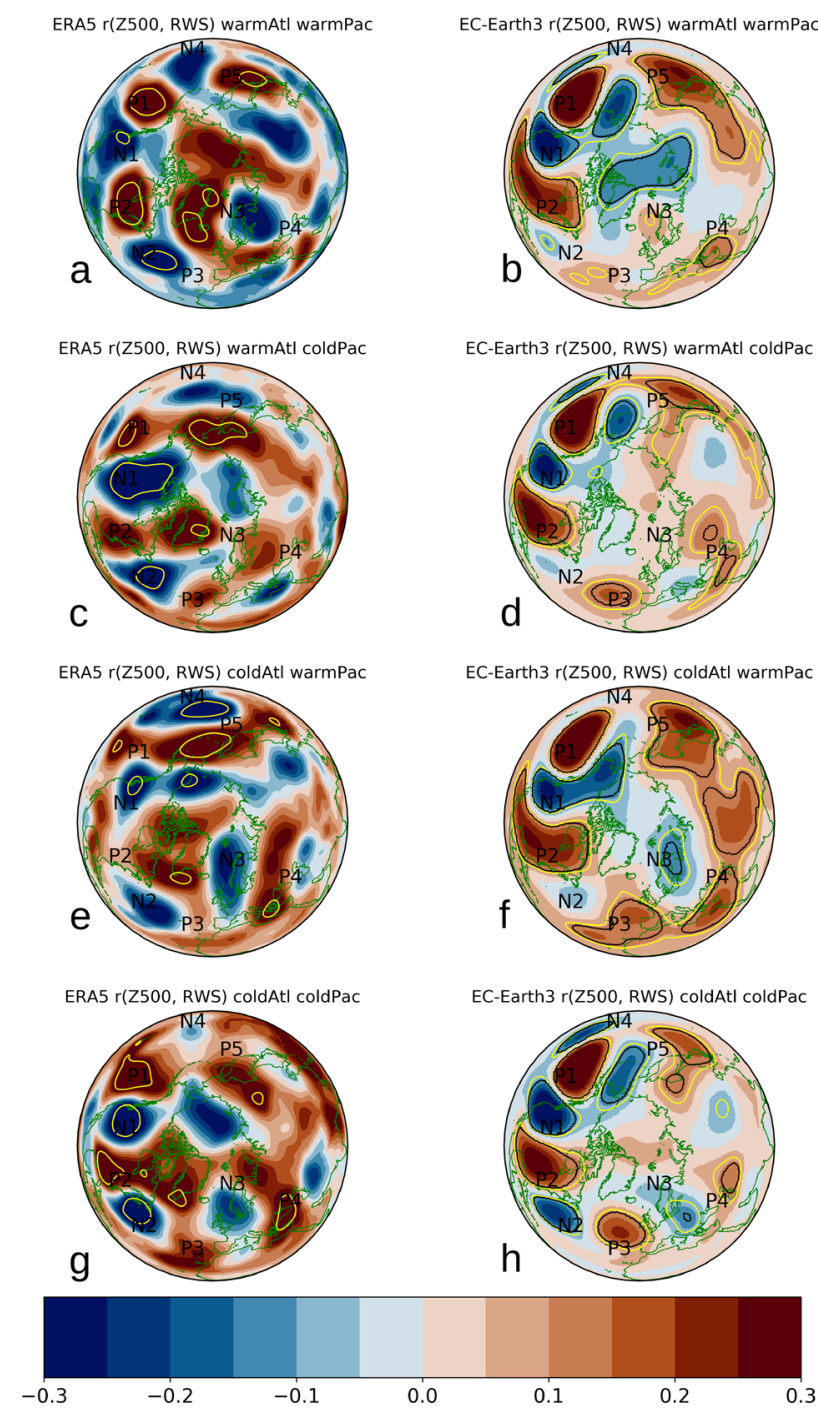

Fig. 10 Pearson correlation between monthly RWS and Z500 for the summer months (June-August) with warm Northeastern Pacific SST and warm North Atlantic for a ERA5 and b SMHI-LENS. c, d As a, b respectively but for summer months with cold Northeastern Pacific and warm North Atlantic. e, $\mathbf{f}$ as $\mathbf{a}, \mathbf{b}$ respectively but for summer months with warm Northeastern Pacific and cold North Atlantic. g, $\mathbf{h}$ as $\mathbf{a}, \mathbf{b}$ respectively but for summer months with cold Northeastern Pacific and cold North Atlantic. Cold and warm Northeastern Pacific and North Atlantic are defined as in Figs. 5, 6, 7 and 8. The periods used are 1979-2018 for ERA5 and 1970-2014 for SMHI-LENS. Yellow contours show the regions that show significant correlation values at $\mathrm{p}<0.05$. Black contours show grid points that passed the Benjamin/Hochberg false discovery rate test with $\alpha=0.1$. The data used to produced the figure was detrended and the monthly climatologies removed

Previously, Saeed et al. (2014) have reported that the positive phase of the CGT causing higher surface pressure over Northern Europe, was related to warm conditions in the western subtropical and North Atlantic Ocean along the Gulf Stream trajectory. During the negative CGT phase, the SST anomalies display significant cold
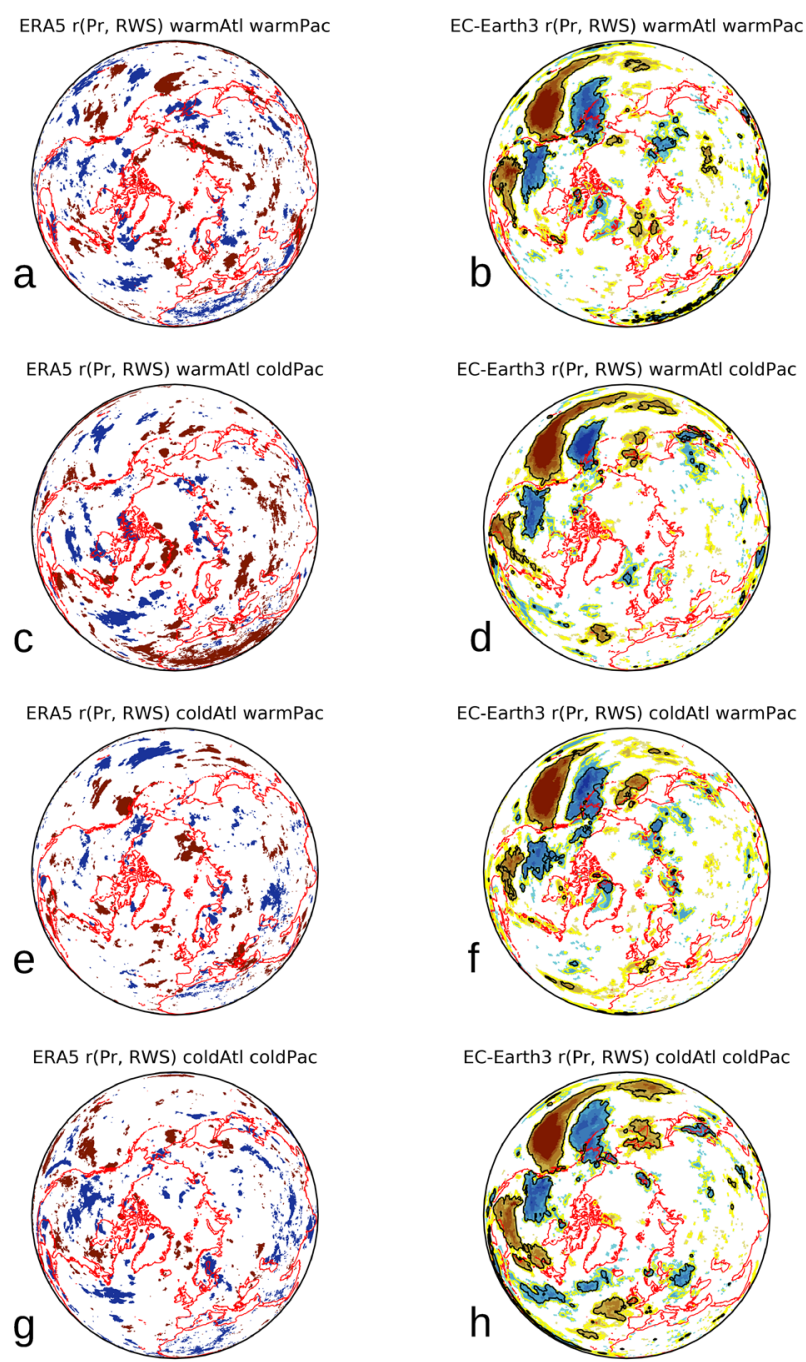

EC-Earth3 r(Pr, RWS) coldAtl coldPac
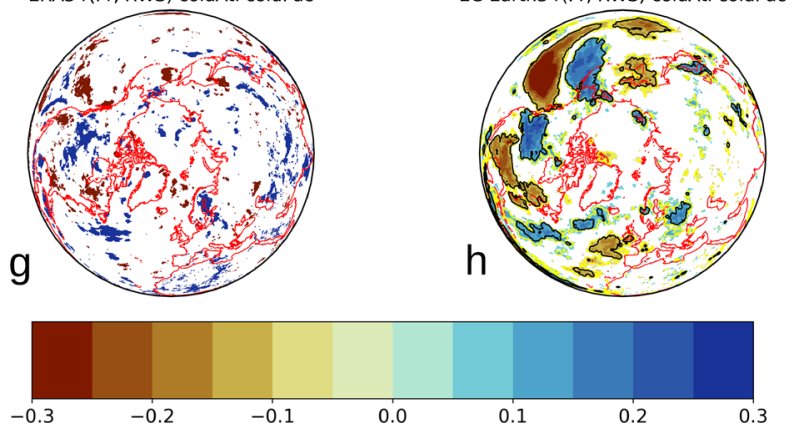

Fig. 11 As Fig. 10 but for precipitation. Only grid points with significant correlation $(\mathrm{p}<0.1)$ are shown

conditions in the North Pacific and the central North Atlantic Ocean, which is consistent with our findings not only from the correlation analysis (Fig. 2c, 6c) but from the analysis regarding the Pacific and North Atlantic states. Our results suggest that RWS emitted in the PacCal region have a strong impact on the CGT phase. The role of the AMO and PDO has also been studied by An et al. (2021) in the context of the CGT; they found that the synergism of the SST in the North Pacific and the northern North Atlantic enhances Rossby wave energy in Eurasia, with more Rossby wave energy spreading that in turn causes the circulation anomaly in the Asian far East. Our results agree with An et al. (2021) and here we provide robust evidence on how different combinations 
of Atlantic and Pacific states modify remote signals that spread around the globe.

All the comparisons between ERA5 and the SMHILENS, must be interpreted considering the following two points: (1) ERA5 although is a reanalysis, and hence it is highly influenced by observations, it is only one realization, and lacks of the different developments of internal climate variability that the large ensemble has, which could be a large cause of mismatch in the different analysis presented. (2) The regions with mismatching between ERA5 and SMHI-LENS might be partially due to models' bias. Regions showing match in the correlation maps in both datasets show that the RWS impact on the global circulation shows some spatial coherence regardless of the datasets.

Both ERA5 with 120 summer months and the SMHILENS with 6750 summer months show that the dynamics of the global atmosphere has linkages to the RWS emitted in the Pacific, and has a characteristic spatial pattern. We also show that the states of both the Pacific and the North Atlantic Oceans (defined by the mean SST) are key factors influencing the shape of this teleconnection.

\section{Conclusions}

The consistency of the results coming from both reanalysis and the EC-Earth3 model large ensemble provides evidence of the influence of the Rossby waves generated over the northeastern Pacific Ocean on the global climate. We show that increased RWS intensity over the northeastern Pacific during summer is related to negative temperature anomalies over western North America, and positive temperature anomalies over eastern North America, concurrently with increased precipitation over the western subtropical Atlantic and Northern Europe during summer.

We also show that Pacific RWS impact the global climate variability, not only of the areas neighbouring the RWS, like the Pacific and North America but also regions farther away like the eastern and western subtropical North Atlantic and Northern Europe, especially during cold phases of the Atlantic and Pacific oceans. Although the results obtained with the global climate model might be subject to internal model biases regarding its atmospheric circulation, wave-like patterns arising from the upper troposphere northeastern Pacific region are a consistent feature across the ensemble members and in many cases consistent with ERA5.

Our results provide robust evidence on how different combinations of Atlantic and Pacific states modulate upper tropospheric remote signals that spread around the globe. Besides the Pacific and North America regions, where the strongest signal is found due to their vicinity to the Pacific RWS, our findings are particularly relevant for Northern Europe, since that region showed a significant correlation between RWS and geopotential height, precipitation and surface temperature. Furthermore, over Northern Europe, ERA5 and SMHI-LENS show a relatively good agreement in terms of correlations between RWS on the one hand and geopotential, temperature and precipitation on the other hand. Knowing how the states of both Atlantic and Pacific oceans impact the upper-tropospheric Rossby waves emitted in the Pacific, and their link to precipitation and surface temperature is helpful to improve seasonal prediction systems. Upcoming studies on how this mechanism is simulated in other climate models will help to better characterize its uncertainty and identify model biases. An assessment of possible future impacts of RWS in model projections should also be carried out.

Supplementary Information The online version contains supplementary material available at https://doi.org/10.1007/s00382-022-06194-4.

Acknowledgements This work was carried out using resources provided by the Swedish National Infrastructure for Computing (SNIC) at the National Supercomputer Centre at Linköping University (NSC).

Funding This study has been made possible by the support of the Rossby Centre at the Swedish Meteorological and Hydrological Institute (SMHI) and the Bolin Centre for Climate Research at Stockholm University.

Data availability ERA5 dataset was downloaded from the Climate Data Store (CDS) of the European Centre for Medium-Range Weather Forecasts (ECMWF-ERA5) online at: https://cds.climate.copernicus. eu/cdsapp\#!/home. Data from the SMHI-LENS are CMIP6 compliant and are available from any ESGF data portal as part of the CMIP6 data holding, with realisation_id's r101 to r150. OSI SAF data is available online from https://resources.marine.copernicus.eu/?option=com csw\&view=details\&product_id=SEAICE_GLO_SEAICE_L4_NRT_ OBSERVATIONS 011001.

\section{Declarations}

Conflict of interest The authors declare that they have no conflict of interest.

Open Access This article is licensed under a Creative Commons Attribution 4.0 International License, which permits use, sharing, adaptation, distribution and reproduction in any medium or format, as long as you give appropriate credit to the original author(s) and the source, provide a link to the Creative Commons licence, and indicate if changes were made. The images or other third party material in this article are included in the article's Creative Commons licence, unless indicated otherwise in a credit line to the material. If material is not included in the article's Creative Commons licence and your intended use is not permitted by statutory regulation or exceeds the permitted use, you will need to obtain permission directly from the copyright holder. To view a copy of this licence, visit http://creativecommons.org/licenses/by/4.0/. 


\section{References}

An X, Sheng L, Li J (2021) Synergistic effect of SST anomalies in the North Pacific and North Atlantic on summer surface air temperature over the Mongolian Plateau. Clim Dyn 56(5):1449-1465

Benjamini Y, Hochberg Y (1995) Controlling the false discovery rate: a practical and powerful approach to multiple testing. J R Stat Soc Ser B (methodological) 57(1):289-300

Branstator G (2002) Circumglobal teleconnections, the jet stream waveguide, and the North Atlantic Oscillation. J Clim 15(14):1893-1910

Deser C, Phillips A, Bourdette V, Teng H (2012) Uncertainty in climate change projections: the role of internal variability. Clim Dyn 38(3-4):527-546

Ding Q, Wang B, Wallace JM, Branstator G (2011) Tropical-extratropical teleconnections in boreal summer: observed interannual variability. J Clim 24:1878-1896. https://doi.org/10.1175/2011J CLI3621.1

Döscher R, Acosta M, Alessandri A, Anthoni P, Arneth A, Arsouze T, Bergmann T, Bernadello R, Bousetta S, Caron LP, Carver G et al (2021) The EC-Earth3 Earth system model for the climate model intercomparison project 6. Geosci Model Dev Discuss. https://doi. org/10.5194/gmd-2020-446

Dunstone N, Scaife AA, MacLachlan C, Knight J, Ineson S, Smith D, Thornton H, Gordon M, McLean PE, Hardiman S, Walker B (2018) Predictability of European winter 2016/2017. Atmos Sci Lett. https://doi.org/10.1002/asl.868

Copernicus Climate Change Service (C3S). 2017. ERA5: fifth generation of ECMWF atmospheric reanalyses of the global climate. Copernicus Climate Change Service Climate Data Store (CDS), date of access. https://cds.climate.copernicus.eu/cdsapp\#!/home

Feldstein SB (2003) The dynamics associated with equatorial atmospheric angular momentum in an aquaplanet GCM. J Atmos Sci 60(15):1822-1834

Fuentes-Franco R, Koenigk T (2020) Identifying remote sources of interannual variability for summer precipitation over Nordic European countries tied to global teleconnection wave patterns. Tellus A Dyn Meteorol Oceanogrsss 72(1):1-15. https://doi.org/10.1080/ 16000870.2020 .1764303

Gastineau G, Frankignoul C (2015) Influence of the North Atlantic SST variability on the atmospheric circulation during the twentieth century. J Clim 28(4):1396-1416. https://doi.org/10.1175/ JCLI-D-14-00424.1

Hersbach H, Bell B, Berrisford P, Hirahara S, Horányi A, MuñozSabater J, Nicolas J, Peubey C, Radu R, Schepers D, Simmons A (2020) The ERA5 global reanalysis. Q J R Meteorol Soc 146(730):1999-2049. https://doi.org/10.1002/qj.3803

Holton JR, Hakim GJ (2004) An introduction to dynamic meteorology. Academic Press, Waltham

Horton DE, Johnson NC, Singh D, Swain DL, Rajaratnam B, Diffenbaugh NS (2015) Contribution of changes in atmospheric circulation patterns to extreme temperature trends. Nature 522:465-469. https://doi.org/10.1038/nature14550

Hoskins BJ, Ambrizzi T (1993) Rossby wave propagation on a realistic longitudinally varying flow. J Atmos Sci 50(12):1661-1671

James IN (1994) Low frequency variability of the circulation. Introduction to Circulating Atmospheres. Cambridge University Press, Cambridge, UK, pp 255-301

Knight JR, Maidens A, Watson PA, Andrews M, Belcher S, Brunet G, Fereday D, Folland CK, Scaife AA, Slingo J (2017) Global meteorological influences on the record UK rainfall of winter 2013-14. Environ Res Lett 12(7):074001

Kornhuber K, Petoukhov V, Petri S, Rahmstorf S, Coumou D (2017) Evidence for wave resonance as a key mechanism for generating high-amplitude quasi-stationary waves in boreal summer. Clim Dyn 49(5-6): 1961-1979

Kornhuber K, Osprey S, Coumou D, Petri S, Petoukhov V, Rahmstorf S, Gray L (2019) Extreme weather events in early summer 2018 connected by a recurrent hemispheric wave- 7 pattern. Environ Res Lett 14(5):054002

Kornhuber K, Coumou D, Vogel E, Lesk C, Donges JF, Lehmann J, Horton RM (2020) Amplified Rossby waves enhance risk of concurrent heatwaves in major breadbasket regions. Nat Clim Chang 10(1):48-53

Lavergne T, Sørensen AM, Kern S, Tonboe R, Notz D, Aaboe S, Bell L, Dybkjær G, Eastwood S, Gabarro C, Heygster G (2019) Version 2 of the EUMETSAT OSI SAF and ESA CCI sea-ice concentration climate data records. Cryosphere 13(1):49-78

Li X, Lu R, Greatbatch RJ, Li G, Hong X (2020a) Maintenance mechanism for the teleconnection pattern over the high latitudes of the Eurasian continent in summer. J Clim 33(3):1017-1030

Li RK, Woollings T, O'Reilly C, Scaife AA (2020b) Tropical atmospheric drivers of wintertime European precipitation events. Q J R Meteorol Soc 146(727):780-794

Luo M, Lau NC (2020) Summer heat extremes in northern continents linked to developing ENSO events. Environ Res Lett 15(7):074042

Neddermann NC, Müller WA, Dobrynin M, Düsterhus A, Baehr J (2019) Seasonal predictability of European summer climate re-assessed. Clim Dyn 53:3039-3018. https://doi.org/10.1007/ s00382-019-04678-4

Nie Y, Zhang Y, Yang XQ, Ren HL (2019) Winter and Summer Rossby Wave Sources in the CMIP5 Models. Earth Space Sci 6(10):1831-1846

O'Reilly CH, Woollings T, Zanna L, Weisheimer A (2018) The impact of tropical precipitation on summertime Euro-Atlantic circulation via a circumglobal wave train. J Climate 31(16):6481-6504

Petoukhov V, Rahmstorf S, Petri S, Schellnhuber HJ (2013) Quasiresonant amplification of planetary waves and recent Northern Hemisphere weather extremes. Proc Natl Acad Sci 110(14):5336-5341

Qin J, Robinson WA (1993) On the Rossby wave source and the steady linear response to tropical forcing. J Atmos Sci 50:1819-1823

Saeed S, Van Lipzig N, Müller WA, Saeed F, Zanchettin D (2014) Influence of the circumglobal wave-train on European summer precipitation. Clim Dyn 43:503-515. https://doi.org/10.1007/ s00382-013-1871-0

Sardeshmukh PD, Hoskins BJ (1988) The generation of global rotational flow by steady idealised tropical divergence. J Atmos Sci 45:1228-1251

Scaife AA, Comer RE, Dunstone NJ, Knight JR, Smith DM, MacLachlan C, Martin N, Peterson KA, Rowlands D, Carroll EB, Belcher S (2017) Tropical rainfall, Rossby waves and regional winter climate predictions. Q J R Meteorol Soc 143(702):1-1

Screen JA, Francis JA (2016) Contribution of sea-ice loss to Arctic amplification is regulated by Pacific Ocean decadal variability. Nat Clim Chang 6(9):856-860

Trenberth KE, Branstator GW, Karoly D, Kumar A, Lau N-C, Ropelewski C (1998) Progress during TOGA in understanding and modelling global teleconnections associated with tropical sea surface temperatures. J Geophys Res 103:14291-14324

Van Oldenborgh GJ, Burgers G, Tank AK (2000) On the El Nino teleconnection to spring precipitation in Europe. Int J Climatol 20:565-574. https://doi.org/10.1002/(SICI)1097-0088(200004) 20:5\%3c565::AID-JOC488\%3e3.0.CO;2-5

Wilks D (2016) "The stippling shows statistically significant grid points": How research results are routinely overstated and overinterpreted, and what to do about it. Bull Am Meteorol Soc 97(12):2263-2273

Wulff CO, Greatbatch RJ, Domeisen DI, Gollan G, Hansen F (2017) Tropical forcing of the Summer East Atlantic pattern. Geophys Res Lett 44:11166-11173 
Wyser K, Koenigk T, Fladrich U, Fuentes-Franco R, Karami MP (2021) The SMHI Large Ensemble (SMHI-LENS) with EC-Earth. Geosci Model Dev (GMD). https://doi.org/10.5194/gmd-2020-428
Publisher's Note Springer Nature remains neutral with regard to jurisdictional claims in published maps and institutional affiliations. 